\title{
Positive Association of Vitamin D Receptor Gene Variations with Multiple Sclerosis in South East Iranian Population
}

\author{
Mehrnaz Narooie-Nejad, ${ }^{1,2}$ Maryam Moossavi, ${ }^{3}$ Adam Torkamanzehi, ${ }^{3}$ and Ali Moghtaderi ${ }^{4}$ \\ ${ }^{1}$ Genetics Department, Zahedan University of Medical Sciences, Zahedan 9816743463, Iran \\ ${ }^{2}$ Genetic of Non-Communicable Disease Research Center, Zahedan University of Medical Sciences, Zahedan 9816743463, Iran \\ ${ }^{3}$ Department of Biology, Sistan and Baluchestan University, Zahedan 98155-987, Iran \\ ${ }^{4}$ Department of Neurology, Zahedan University of Medical Sciences, Zahedan 9816743463, Iran
}

Correspondence should be addressed to Mehrnaz Narooie-Nejad; mehrnaznar@gmail.com and Ali Moghtaderi; amoghtaderi@gmail.com

Received 9 August 2014; Revised 23 December 2014; Accepted 24 December 2014

Academic Editor: Frederic Blanc

Copyright (C) 2015 Mehrnaz Narooie-Nejad et al. This is an open access article distributed under the Creative Commons Attribution License, which permits unrestricted use, distribution, and reproduction in any medium, provided the original work is properly cited.

\begin{abstract}
Among the factors postulated to play a role in MS susceptibility, the role of vitamin D is outstanding. Since the function of vitamin D receptor (VDR) represents the effect of vitamin D on the body and genetic variations in VDR gene may affect its function, we aim to highlight the association of two VDR gene polymorphisms with MS susceptibility. In current study, we recruited 113 MS patients and 122 healthy controls. TaqI (rs731236) and ApaI (rs7975232) genetic variations in these two groups were evaluated using the polymerase chain reaction-restriction fragment length polymorphism (PCR-RFLP) technique. All genotype and allele frequencies in both variations showed association with the disease status. However, to find the definite connection between genetic variations in VDR gene and MS disease in a population of South East of Iran, more researches on gene structure and its function with regard to patients' conditions are required.
\end{abstract}

\section{Introduction}

Multiple sclerosis (MS) (OMIM126200) is a chronic inflammatory, neurodegenerative, demyelinating, and accumulating debilitative disease of the central nervous system (CNS) with a complex etiology that affects over 2.1 million people worldwide [1]. Like most complicated disorders, genetic and environmental elements play a chief role, whether in synergistic or in independent manners [2]. Thus far, many genes have been identified in predisposing to MS disease. Genomewide association studies (GWAS) suggested more than 20 loci in MS susceptibility, including vitamin D receptor (VDR) gene $[3,4]$. According to the recent studies of the role of vitamin D in MS, this association seems reasonable. Vitamin $\mathrm{D}$ as a secosteroid hormone is predominantly produced from 7-dehydrocholesterol in the skin during the exposure to ultraviolet (UV) radiation of the sunlight and by dietary intake as well. The active form of vitamin $\mathrm{D}$ (1,25-dihydroxyvitamin $\mathrm{D}_{3}$ ) is identified as a ligand for VDR.
The VDR is an intracellular polypeptide that belongs to the steroid-thyroid-retinoid acid receptor superfamily. It binds to the DNA in target cells as VDR/VDR homodimers or VDR/RXR heterodimers in order to initiate the synthesis of special RNA encoding proteins that activates a range of biological functions or mediates suppression of gene transcriptions [5-7].

VDR gene is mapped on chromosome 12q12-14 and contains 9 exons and 8 introns [8]. Some studies suggested that the role of vitamin $\mathrm{D}$ in the pathogenesis of MS is through its strong immune-modulating effect $[9,10]$. Furthermore, increasing data have provided facts that $1,25-(\mathrm{OH})_{2} \mathrm{D}_{3}$ is involved in brain function. Hence, the nuclear receptor for $1,25-(\mathrm{OH})_{2} \mathrm{D}_{3}$ has been concentrated in neurons and glial cells in order to operate its function [11]. Vitamin D exerts a direct impact on T-lymphocyte proliferation notably by upregulating $\mathrm{T}$ regulatory cells in the presence of active form of vitamin $\mathrm{D}$ [12], along with reduction of proinflammatory cytokine, interferon-gamma, production [13]. It has been 
found that high amounts of IFN- $\gamma$ exist in sera, plasma, and lesions of individuals affected with MS [14]. Furthermore, vitamin $\mathrm{D}_{3}$ inhibits $\mathrm{B}$ cell proliferation by increasing the cell cycle check point, p27, and induces apoptosis in activated $\mathrm{B}$ cells, thus reducing antibody production via its nuclear hormone receptor [15]. Neuroprotective and immunomodulatory influences of this hormone have been explained in several experimental models as well. Alternative studies reported that MS individuals have also low serum levels of vitamin $\mathrm{D}$ and this condition is manifested by increasing rates of bone fractures happening in MS patients in comparison to healthy people [16]. Investigations on an MS animal model, experimental autoimmune encephalomyelitis (EAE), have shown an absolute inhibition of disease course following the injection of the biologically active form of vitamin $\mathrm{D}$ [17]. Moreover, studies of VDR knockout mice show that absence of VDR is crucial for EAE activity [18]. By these findings, VDR and its ligand show relative immunosuppressive and anti-inflammatory role. Several studies have confirmed the variation of genes in different individuals [19]. The VDR polymorphisms have been reported to be linked with an increased risk of several autoimmune diseases including MS [20-22]. Specific variations of the VDR gene may alter vitamin $\mathrm{D}$ function and metabolism and have been investigated in studies evaluating the function of vitamin D on MS [23]. These findings suggest that allelic variation of the VDR gene may at least partially represent the genetic component of MS disease. By these genetic findings and the probable importance of the VDR in MS, we sought to investigate the relationship between the VDR gene two single nucleotide polymorphisms, TaqI (rs731236) and ApaI (rs7975232), and MS susceptibility in South East Iranian population.

\section{Material and Methods}

2.1. Study Population. A total of 235 subjects were recruited in this study, including 113 MS patients clinically diagnosed with MS according to McDonald's criteria [24] and 122 agedmatched controls free from any neurologic and systemic disorder. All patients referred to Imam Ali University Hospital in Zahedan, Sistan and Baluchistan province of Iran. All participants provided informed consent according to the Declaration of Helsinki and accepted codes of the university ethics committee.

2.2. Genotyping of VDRG Polymorphisms. Genomic DNA was extracted from the whole blood samples provided from each subject by using salting out protocol [25]. The ApaI and TaqI polymorphisms were identified using the polymerase chain reaction-restriction fragment length polymorphism (PCR-RFLP) technique. The primers sequences which were used to amplify the target fragments containing the polymorphisms to be studied are shown in Table 1. The annealing temperature for ApaI and TaqI single nucleotide polymorphisms (SNP) was $68^{\circ} \mathrm{C}$ and $65^{\circ} \mathrm{C}$, respectively. The ApaI and TaqI enzymes were used to distinguish the related SNPs. Digested products were separated by electrophoresis on a $2.5 \%$ agarose gel and visualized by ethidium bromide staining.
2.3. Statistical Analysis. The distribution of genotypes and alleles in patients and healthy controls was evaluated for deviation from Hardy-Weinberg Equilibrium. Data were analyzed by using the statistical software SPSS 18 (SPSS, Chicago, IL). Differences in genotypic and allelic distribution between patients and controls were determined by independent sample $t$-test and Chi-square $\left(\chi^{2}\right)$ test. The odds ratio (OR) and 95\% confidence intervals (CI) were also estimated. Values of $P<0.05$ were considered statistically significant.

\section{Result}

113 MS patients ( 88 women and 25 men) with a mean age of $32.4 \pm 8.9$ and 122 unrelated healthy controls (94 women and 28 men) with a mean age of $30.8 \pm 10.2$ were recruited to our study. Age and sex adjustment were performed between the two groups. The mean age of onset for these patients is $28.6 \pm$ 8.6. Genotype frequencies for TaqI and ApaI polymorphisms hold the Hardy-Weinberg equilibrium $(P>0.05)$.

As it has been shown in Table 2, positive associations with MS were found in CC $(P$ values $<0.0001$; OR $=313$, 95\% CI in 65.5-1500) and TC genotypes $(P$ values $<0.0001$; $\mathrm{OR}=17.7,95 \% \mathrm{CI}$ in 7.6-40.9) and negative association was found with the disease in the TT genotype for TaqI (rs731236) polymorphism. The frequency of $\mathrm{C}$ allele of TaqI polymorphism was significantly higher in patients than in controls ( $P$ values < 0.0001; OR $=18.9,95 \%$ CI in 11.6-30.3); it can be concluded that allele $\mathrm{C}$ showed positive association and allele T showed negative association with MS. In the ApaI single nucleotide polymorphism investigation (rs7975232), homozygote genotype CC was significantly higher in patients $(P=0.036$; OR $=3.4,95 \% \mathrm{CI}$ in 1.1-10.4) in comparison to controls. However, the AA genotype frequency indicated negative associations with MS too. Furthermore, allele frequency of $\mathrm{C}$ was in positive association with $\mathrm{MS}(P$ values $=0.019)$. The calculated value of $P$ for AC genotype in ApaI was around the significant area $(P=0.056)$. For better evaluation, more samples are needed to clarify this relationship, which was not available to us.

\section{Discussion}

Several studies have been conducted on the impact of environmental elements on the rate of MS morbidity [26]. It appears that the frequency of vitamin D deficiency has a significant role in causing the disease [27]. So far, several publications are released regarding association of MS with vitamin $\mathrm{D}$ concentration in serum and cerebrospinal fluid. But with the conflicting results obtained, further investigation is needed [27-30]. Since the role of vitamin D in MS is still the subject of investigations, it is reasonable to evaluate the role of the VDR in MS susceptibility. In fact, the function of VDR represents the effect of vitamin D in the body and genetic variations in VDR gene may affect its function. In this regard, 113 MS patients and 122 matched controls in Sistan and Baluchestan province were genotyped for two SNPs, ApaI and TaqI, in VDR gene. This is approximately a distinct population in South East of Iran, with an intermediate 
TABle 1: Primer sequences for ApaI and TaqI polymorphisms.

ApaI (rs7975232)

TaqI (rs731236)
F: $5^{\prime}$-AGAGCATGGACAGGGAGCAAGGCCAGGCAG- $3^{\prime}$ R: $5^{\prime}$-GCGCAGGTCGGCTAGCTTCTGGATCATC- $3^{\prime}$

F: $5^{\prime}$-GGGACGATGAGGGATGGACAGAGC- $3^{\prime}$

R: $5^{\prime}$-GGAAAGGGGTTAGGTTGGACAGGA- $3^{\prime}$

TABLE 2: Genotype and allele frequencies of TaqI (rs731236) and ApaI (rs7975232).

\begin{tabular}{|c|c|c|c|c|c|c|}
\hline SNP & Genotype/allele & $\begin{array}{l}\text { Patients } \\
n=113\end{array}$ & $\begin{array}{c}\text { Controls } \\
n=122\end{array}$ & $\begin{array}{c}\text { Odds ratio } \\
(95 \% \mathrm{CI})\end{array}$ & $P$ value & $\begin{array}{c}\text { Power study } \\
(\%)\end{array}$ \\
\hline \multirow{5}{*}{ TaqI (rs731236) } & $\mathrm{TT}, n(\%)$ & $9(8)$ & $94(77)$ & 1 & & 100 \\
\hline & TC, $n(\%)$ & $44(39)$ & $26(21.4)$ & $17.7(7.6-40.9)$ & $<0.0001$ & 80.54 \\
\hline & CC, $n(\%)$ & $60(53)$ & $2(1.6)$ & $313(65.5-1500)$ & $<0.0001$ & 100 \\
\hline & $\mathrm{T}, n(\%)$ & $62(27.4)$ & $214(87.7)$ & 1 & & \\
\hline & C, $n(\%)$ & $164(72.6)$ & $30(12.3)$ & $18.9(11.6-30.3)$ & $<0.0001$ & 100 \\
\hline \multirow{5}{*}{ ApaI (rs7975232) } & AA & $40(35.4)$ & $61(50)$ & 1 & & 56.61 \\
\hline & $\mathrm{AC}$ & $62(54.9)$ & $56(45.9)$ & $1.7(1-2.9)$ & 0.056 & 23.34 \\
\hline & $\mathrm{CC}$ & $11(9.7)$ & $5(4.1)$ & $3.4(1.1-10.4)$ & 0.036 & 29.81 \\
\hline & A & $142(62.8)$ & $178(73)$ & 1 & & \\
\hline & $\mathrm{C}$ & $84(37.2)$ & $66(27)$ & $1.6(1.1-2.4)$ & 0.019 & 32.77 \\
\hline
\end{tabular}

TaqI genotypes $(\mathrm{TT}=$ wild type; $\mathrm{TC}=$ heterozygote; $\mathrm{CC}=$ mutant type); ApaI genotypes $(\mathrm{AA}=$ wild type; $\mathrm{AC}=$ heterozygote; $\mathrm{CC}=$ mutant type).

prevalence of MS, along with a fast growing incidence rate $[31,32]$. Although these variations do not cause a change in protein structure, their proximity to the $3^{\prime} \mathrm{UTR}$ may affect the translation process or signaling pathway. One study concluded that the gene expression in $\mathrm{C}$ (mutant) allele is $30 \%$ less than that in $\mathrm{T}$ (wild) allele in TaqI variation [33]. In current study, all genotype and allele frequencies in both variations showed association with the disease status. These results are in contrast with the results obtained from Greece [23], USA $[19,33]$, and Netherlands [34], which believe that there is no association between VDRG polymorphisms and MS disease. Compared to these studies, other surveys in Japan [22, 35], Australia [36], and UK [37] have shown that there are associations between VDRG polymorphisms and MS. It is clear that, with the present data, a definite conclusion cannot be reached in this area.

Note that, in this province, there are no significant differences in the concentration of 25-OH-D3 calcium levels in the serum and cerebrospinal fluid (CSF) in MS patients compared with the control group [28].

Although we could not yet definitely emphasize the role of polymorphisms on VDR function, consider that the variation in vitamin $\mathrm{D}$ receptor may affect the ligand-receptor affinity or signaling pathway [38] or gene expression [33] and so indirectly affect the function of vitamin D.

If these polymorphisms are nonfunctional, the possibility arises that these polymorphisms are in linkage disequilibrium (LD) with other factors that affect gene function [38].

However, to find the actual relationship between genetic variations and MS disease, extensive research on gene structure and its function in regard to patients' conditions is required.

\section{Conflict of Interests}

The authors declare that there is no conflict of interests regarding the publication of this paper.

\section{References}

[1] M. Muñoz-Culla, H. Irizar, and D. Otaegui, "The genetics of multiple sclerosis: review of current and emerging candidates," Application of Clinical Genetics, vol. 6, pp. 63-73, 2013.

[2] M. M. Goldenberg, "Multiple sclerosis review," $P$ \& $T$, vol. 37, no. 3, pp. 175-184, 2012.

[3] J.-I. Satoh and H. Tabunoki, "Molecular network of chromatin immunoprecipitation followed by deep sequencing-based vitamin D receptor target genes," Multiple Sclerosis, vol. 19, no. 8, pp. 1035-1045, 2013.

[4] N. A. Patsopoulos, Bayer Pharma MS Genetics Working Group, Steering Committees of Studies Evaluating IFN $\beta-1 b$ and a CCR1-Antagonist et al., "Genome-wide meta-analysis identifies novel multiple sclerosis susceptibility loci," Annals of Neurology, vol. 70, no. 6, pp. 897-912, 2011.

[5] P. J. Malloy, T. R. Eccleshall, C. Gross, L. van Maldergem, R. Bouillon, and D. Feldman, "Hereditary vitamin D resistant rickets caused by a novel mutation in the vitamin $\mathrm{D}$ receptor that results in decreased affinity for hormone and cellular hyporesponsiveness," Journal of Clinical Investigation, vol. 99, no. 2, pp. 297-304, 1997.

[6] B. Cheskis and L. P. Freedman, "Ligand modulates the conversion of DNA-bound vitamin D3 receptor (VDR) homodimers into VDR-retinoid X receptor heterodimers," Molecular and Cellular Biology, vol. 14, no. 5, pp. 3329-3338, 1994.

[7] L. L. Issa, G. M. Leong, and J. A. Eisman, "Molecular mechanism of vitamin D receptor action," Inflammation Research, vol. 47, no. 12 , pp. 451-475, 1998. 
[8] N. A. Morrison, J. C. Qi, A. Tokita et al., "Prediction of bone density from vitamin D receptor alleles," Nature, vol. 367, no. 6460, pp. 284-287, 1994.

[9] M. Hewison, "Vitamin D and the immune system: new perspectives on an old theme," Rheumatic Disease Clinics of North America, vol. 38, no. 1, pp. 125-139, 2012.

[10] P. W. Jurutka, L. Bartik, G. K. Whitfield et al., "Vitamin D receptor: key roles in bone mineral pathophysiology, molecular mechanism of action, and novel nutritional ligands," Journal of Bone and Mineral Research, vol. 22, supplement 2, pp. V2-V10, 2007.

[11] E. Garcion, N. Wion-Barbot, C. N. Montero-Menei, F. Berger, and D. Wion, "New clues about vitamin D functions in the nervous system," Trends in Endocrinology \& Metabolism, vol. 13, no. 3, pp. 100-105, 2002.

[12] S. Gorman, L. A. Kuritzky, M. A. Judge et al., “Topically applied 1,25-dihydroxyvitamin $\mathrm{D}_{3}$ enhances the suppressive activity of $\mathrm{CD} 4{ }^{+} \mathrm{CD} 25^{+}$cells in the draining lymph nodes," The Journal of Immunology, vol. 179, no. 9, pp. 6273-6283, 2007.

[13] A. Boonstra, F. J. Barrat, C. Crain, V. L. Heath, H. F. J. Savelkoul, and A. O'Garra, " $1 \alpha, 25$-Dihydroxyvitamin D3 has a direct effect on naive $\mathrm{CD} 4{ }^{+} \mathrm{T}$ cells to enhance the development of Th2 cells," Journal of Immunology, vol. 167, no. 9, pp. 4974-4980, 2001.

[14] H. M. Schrijver, T. Hooper-van Veen, M. J. van Belzen et al., "Polymorphisms in the genes encoding interferon- $\gamma$ and interferon- $\gamma$ receptors in multiple sclerosis," European Journal of Immunogenetics, vol. 31, no. 3, pp. 133-140, 2004.

[15] S. Chen, G. P. Sims, X. C. Xiao, Y. G. Yue, S. Chen, and P. E. Lipsky, "Modulatory effects of 1,25-dihydroxyvitamin D3 on human B cell differentiation," Journal of Immunology, vol. 179, no. 3, pp. 1634-1647, 2007.

[16] J. Nieves, F. Cosman, J. Herbert, V. Shen, and R. Lindsay, "High prevalence of vitamin D deficiency and reduced bone mass in multiple sclerosis," Neurology, vol. 44, no. 9, pp. 1687-1692, 1994.

[17] M. T. Cantorna, C. E. Hayes, and H. F. Deluca, "1,25dihydroxyvitamin D3 reversibly blocks the progression of relapsing encephalomyelitis, a model of multiple sclerosis," Proceedings of the National Academy of Sciences of the United States of America, vol. 93, no. 15, pp. 7861-7864, 1996.

[18] T. F. Meehan and H. F. DeLuca, "The vitamin D receptor is necessary for $1 \alpha, 25$-dihydroxyvitamin $\mathrm{D}_{3}$ to suppress experimental autoimmune encephalomyelitis in mice," Archives of Biochemistry and Biophysics, vol. 408, no. 2, pp. 200-204, 2002.

[19] K. C. Simon, K. L. Munger, X. Yang, and A. Ascherio, "Polymorphisms in vitamin D metabolism related genes and risk of multiple sclerosis," Multiple Sclerosis, vol. 16, no. 2, pp. 133-138, 2010.

[20] V. Škrabić, T. Zemunik, M. Šitum, and J. Terzić, "Vitamin D receptor polymorphism and susceptibility to type 1 diabetes in the Dalmatian population," Diabetes Research and Clinical Practice, vol. 59, no. 1, pp. 31-35, 2003.

[21] C.-M. Huang, M.-C. Wu, J.-Y. Wu, and F.-J. Tsai, "Association of vitamin D receptor gene BsmI polymorphisms in Chinese patients with systemic lupus erythematosus," Lupus, vol. 11, no. 1, pp. 31-34, 2002.

[22] M. Niino, T. Fukazawa, I. Yabe, S. Kikuchi, H. Sasaki, and K. Tashiro, "Vitamin D receptor gene polymorphism in multiple sclerosis and the association with HLA class II alleles," Journal of the Neurological Sciences, vol. 177, no. 1, pp. 65-71, 2000.

[23] C. Sioka, S. Papakonstantinou, S. Markoula et al., "Vitamin D receptor gene polymorphisms in multiple sclerosis patients in northwest Greece," Journal of Negative Results in BioMedicine, vol. 10, no. 1, article 3, 2011.

[24] C. H. Polman, S. C. Reingold, G. Edan et al., "Diagnostic criteria for multiple sclerosis: 2005 revisions to the "McDonald Criteria'”' Annals of Neurology, vol. 58, no. 6, pp. 840-846, 2005.

[25] M. Mohammadoo-Khorasani, S. Salimi, E. Tabatabai, M. Sandoughi, and Z. Zakeri, "Association of interleukin-1 receptor antagonist gene 86bp VNTR polymorphism with systemic lupus erythematosus in south east of Iran," Zahedan Journal of Research in Medical Sciences, vol. 16, no. 12, pp. 51-54, 2014.

[26] C. O’Gorman, R. Lucas, and B. Taylor, "Environmental risk factors for multiple sclerosis: a review with a focus on molecular mechanisms," International Journal of Molecular Sciences, vol. 13, no. 9, pp. 11718-11752, 2012.

[27] B. M. VanAmerongen, C. D. Dijkstra, P. Lips, and C. H. Polman, "Multiple sclerosis and vitamin D: an update," European Journal of Clinical Nutrition, vol. 58, no. 8, pp. 1095-1109, 2004.

[28] A. Moghtaderi, G. H. Tamadon, and F. Haghighi, "25hydroxyvitamin D3 concentration in serum and cerebrospinal fluid of patients with remitting-relapse multiple sclerosis," Prague Medical Report, vol. 114, no. 3, pp. 162-171, 2013.

[29] C. J. Willer, D. A. Dyment, A. D. Sadovnick, P. M. Rothwell, T. J. Murray, and G. C. Ebers, "Timing of birth and risk of multiple sclerosis: population based study," British Medical Journal, vol. 330, no. 7483, pp. 120-123, 2005.

[30] A. Ascherio, K. L. Munger, and K. C. Simon, "Vitamin D and multiple sclerosis," The Lancet Neurology, vol. 9, no. 6, pp. 599612, 2010.

[31] M. Etemadifar, S. Sajjadi, Z. Nasr et al., "Epidemiology of multiple sclerosis in iran: a systematic review," European Neurology, vol. 70, no. 5-6, pp. 356-363, 2013.

[32] A. Moghtaderi, F. Rakhshanizadeh, and S. Shahraki-Ibrahimi, "Incidence and prevalence of multiple sclerosis in southeastern Iran," Clinical Neurology and Neurosurgery, vol. 115, no. 3, pp. 304-308, 2013.

[33] L. K. Durrin, R. W. Haile, S. A. Ingles, and G. A. Coetzee, "Vitamin D receptor 3'-untranslated region polymorphisms: lack of effect on mRNA stability," Biochimica et Biophysica Acta-Molecular Basis of Disease, vol. 1453, no. 3, pp. 311-320, 1999.

[34] J. Smolders, J. Damoiseaux, P. Menheere, J. W. C. Tervaert, and R. Hupperts, "Association study on two vitamin D receptor gene polymorphisms and vitamin D metabolites in multiple sclerosis," Annals of the New York Academy of Sciences, vol. 1173, no. 1, pp. 515-520, 2009.

[35] T. Fukazawa, I. Yabe, S. Kikuchi et al., "Association of vitamin $\mathrm{D}$ receptor gene polymorphism with multiple sclerosis in Japanese," Journal of the Neurological Sciences, vol. 166, no. 1, pp. 47-52, 1999.

[36] L. Tajouri, M. Ovcaric, R. Curtain et al., "Variation in the vitamin $\mathrm{D}$ receptor gene is associated with multiple sclerosis in an Australian population," Journal of Neurogenetics, vol. 19, no. 1, pp. 25-38, 2005.

[37] J. M. Partridge, S. J. M. Weatherby, J. A. Woolmore et al., "Susceptibility and outcome in MS: associations with polymorphisms in pigmentation-related genes," Neurology, vol. 62, no. 12, pp. 2323-2325, 2004.

[38] A. G. Uitterlinden, Y. Fang, J. B. J. Van Meurs, H. Van Leeuwen, and H. A. P. Pols, "Vitamin D receptor gene polymorphisms in relation to Vitamin D related disease states," The Journal of Steroid Biochemistry and Molecular Biology, vol. 89-90, pp. 187193, 2004. 

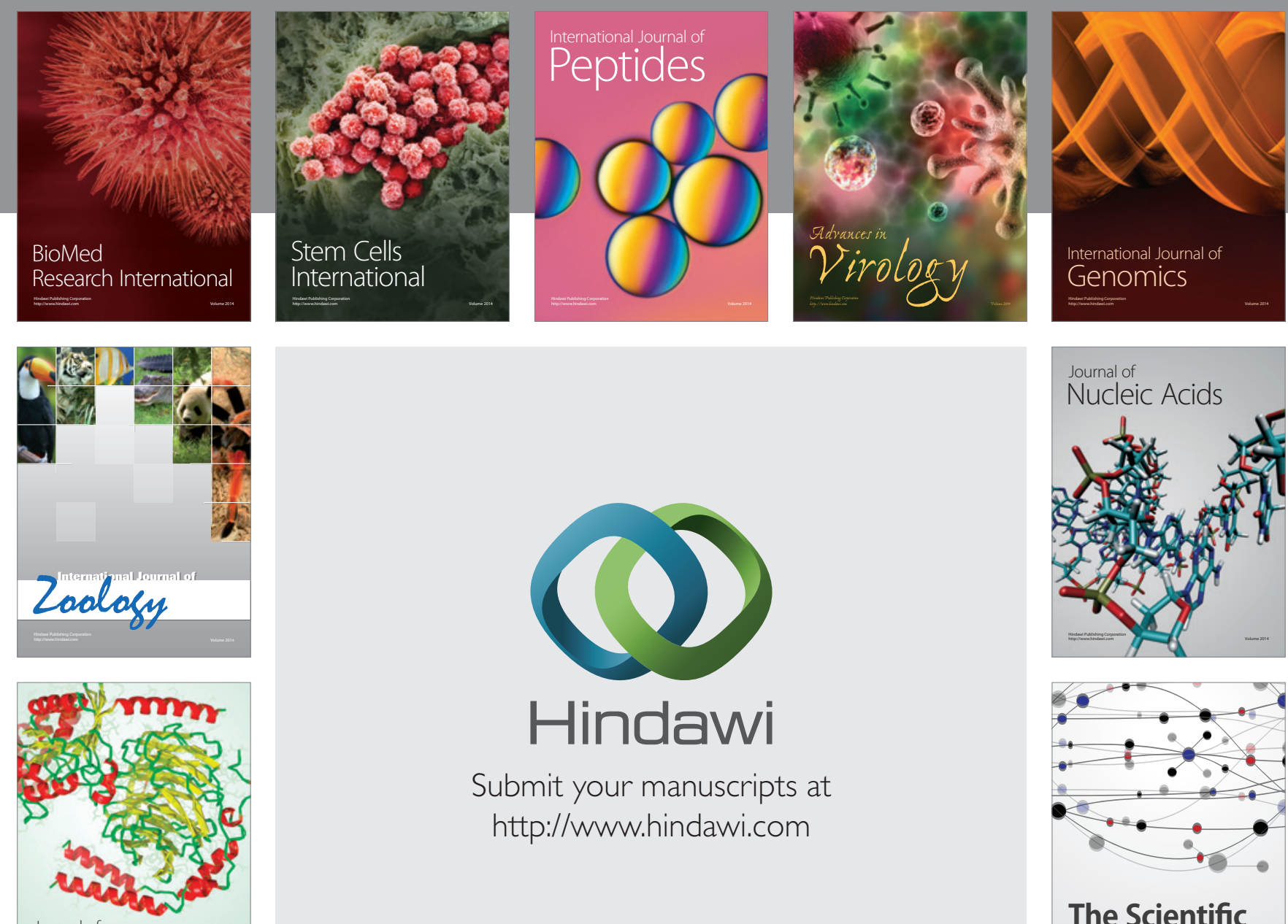

Submit your manuscripts at

http://www.hindawi.com

Journal of
Signal Transduction
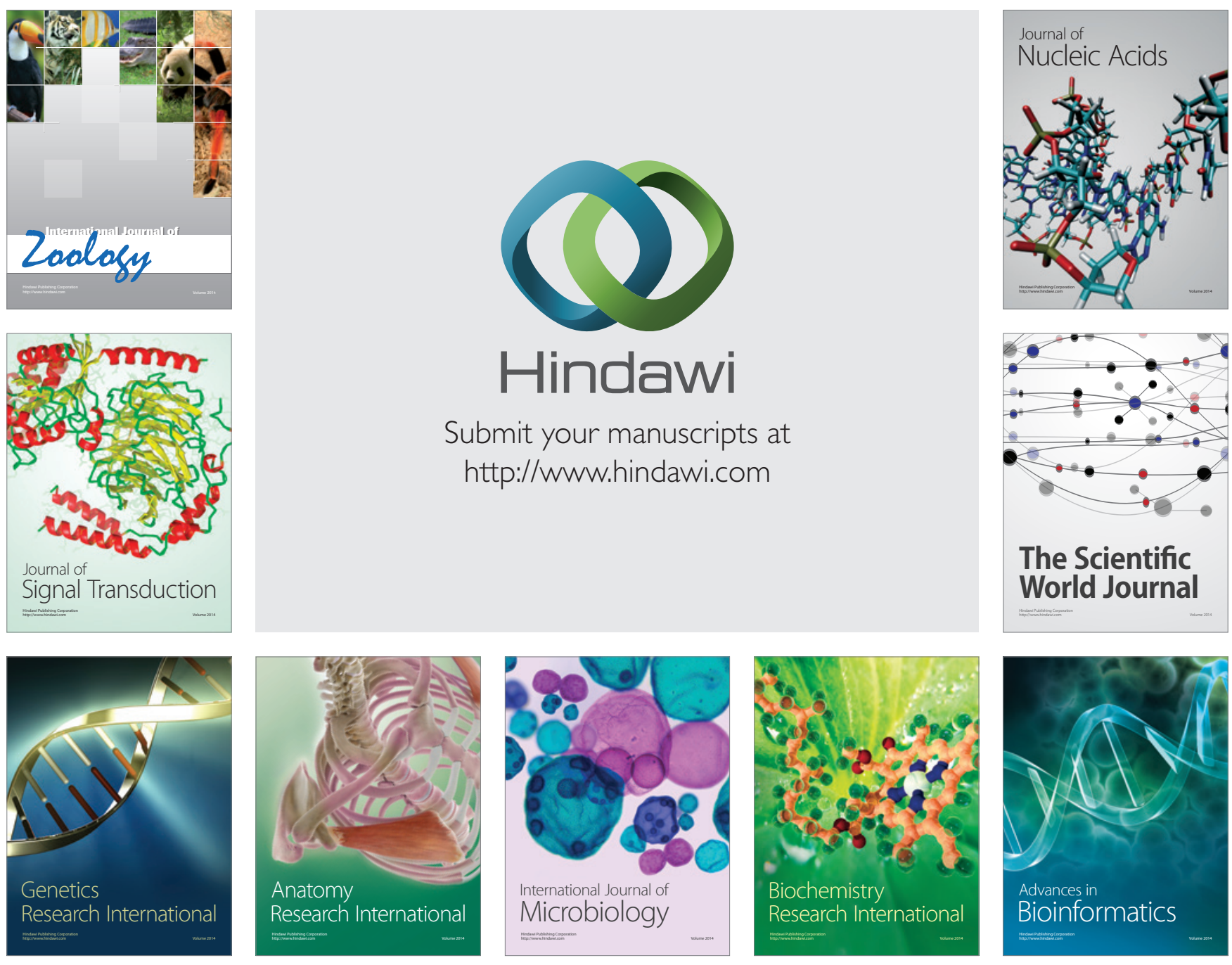

The Scientific World Journal
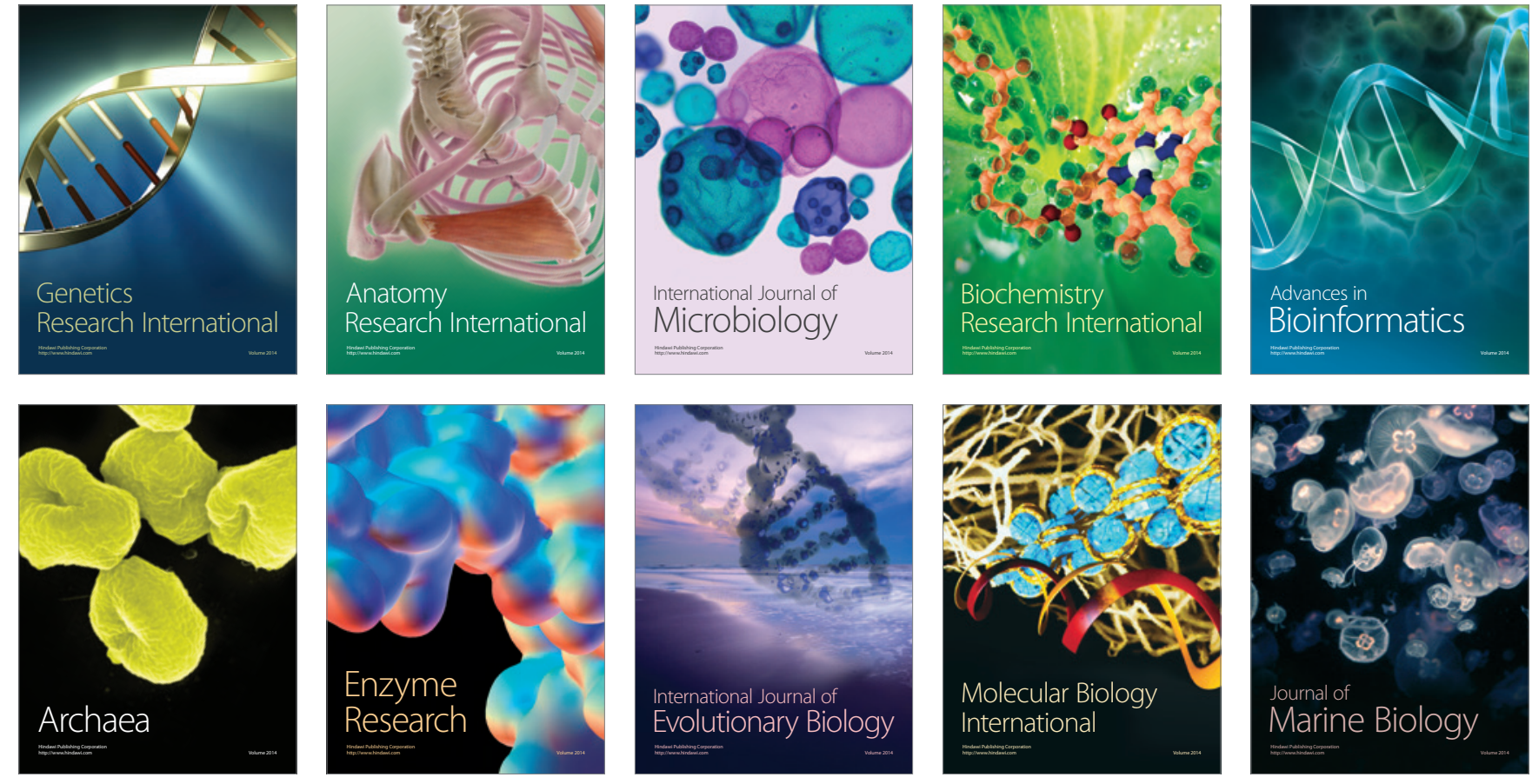